\title{
Kinetic and Thermodynamics of Methylene Blue Adsorption onto Zero Valent Iron Supported on Mesoporous Silica
}

\author{
Atyaf Khalid Hameed ${ }^{1 *}$, Nugroho Dewayanto², Du Dongyun ${ }^{3}$, Mohd Ridzuan Nordin ${ }^{4}$, \\ Mohd Hasbi Ab. Rahim ${ }^{1}$ \\ ${ }^{1}$ Faculty of Industrial Sciences \& Technology, Universiti Malaysia Pahang, Lebuhraya Tun Razak \\ 26300 Kuantan, Pahang, Malaysia \\ ${ }^{2}$ Universiti Kuala Lumpur, Malaysian Institute of Chemical and Bioengineering Technology, \\ Vendor City 1988, 78000 Alor Gajah, Melaka, Malaysia \\ ${ }^{3}$ Key Laboratory for Catalysis and Materials Science of the State Ethnic Affairs Commissions \& \\ Ministry of Education, South Central University for Nationalties, Wuhan 430074, China \\ ${ }^{4}$ Faculty of Technology Management and Technopreneurship, Universiti Teknikal Malaysia \\ Melaka, Hang Tuah Jaya, 76100 Durian Tunggal, Melaka, Malaysia
}

Received: $5^{\text {th }}$ March 2016; Revised: 18 ${ }^{\text {th }}$ March 2016; Accepted: $18^{\text {th }}$ March 2016

\section{Abstract}

Zero valent iron supported on mesoporous silicanano particles (NZVI/MSNs) was prepared by the aqueous phase borohydride reduction methods. Prior to the reduction, mesoporous silica nanoparticles (MSNs) were prepared through the activation of fumed silica with concentrated $\mathrm{HCl}$ by refluxing at 90 ${ }^{\circ} \mathrm{C}$. FTIR, XRD, FESEM, EDX and BET were used to characterize theadsorbents prepared. BET surface areas of MSNs, NZVI, and NZVI/MSNs were 126, 41, and $72 \mathrm{~m}^{2} / \mathrm{g}$ for, respectively. The performance of NZVI/MSNs as adsorbent was examined by adsorption of methylene blue (MB), performed in series of batch experiments. In the kinetic studies, pseudo first order and pseudo second order kinetic models were examined. The pseudo second order equation provided the best fit with the experimental data. Thermodynamic studies indicated that the adsorption process is endothermic with $\Delta \mathrm{H}^{\circ}$ was $90.53 \mathrm{~kJ} / \mathrm{mol}$. Positive $\Delta \mathrm{S}^{\circ}(300 \mathrm{~J} / \mathrm{mol})$ and negative $\Delta \mathrm{G}^{\circ}(-6.42 \mathrm{~kJ} / \mathrm{mol})$ was recorded, indicating the spontaneous of the adsorption process and naturally favorable. Copyright (C) 2016 BCREC GROUP. All rights reserved

Keywords: zero valent iron; adsorption kinetics; adsorption thermodynamics; methylene blue; mesoporous silica

How to Cite: Hameed, A.K., Dewayanto, N., Dongyun, D., Nordin, M.R., Rahim, M.H.A. (2016). Kinetic and Thermodynamics of Methylene Blue Adsorption onto Zero Valent Iron Supported on Mesoporous Silica. Bulletin of Chemical Reaction Engineering \& Catalysis, 11 (2): 250-261 (doi:10.9767/bcrec.11.2.443.250-261)

Permalink/DOI: http://dx.doi.org/10.9767/bcrec.11.2.443.250-261

\section{Introduction}

The dye pollution from industries, particularly generated from the effluent of textile,

* Corresponding Author.

E-mail: atyaf.ump2015@gmail.com (A.K. Hameed) leather, food processing, dyeing, cosmetics, paper, and dye manufacturing industries becomes serious concern since their toxicity to living organism [1, 2]. Moreover, the colour appearance in water bodies is unpleasant and disturbing the people. Therefore, removal of dyes becomes important aspects of wastewater treatment before discharging it into environment. Unfortu- 
nately, dyes are not easily degradable and are generally not removed from wastewater by conventional wastewater systems [3]. For these reasons, colour removal is extensively studied with physical-chemical methods as coagulation, ultra-filtration, electro-chemical adsorption and photo-oxidation [4]. Among these methods, adsorption is widely used for dye removal from wastewater, due to its simplicity in operation and effective for low concentration of pollutant [5]. Numerous studies have been done on dyes adsorption kinetics, equilibrium modelling, and mechanism as well as to the factors that affect adsorption. Recently, mesoporous materials such as MCM-41 have also received a considerable recognition due to their large pore-space and special surface property [6]. Porous materials have attracted the attention of scientists due to commercial interest related to their applications in separations, catalysts, and purification technologies. In the last decade, intensive scientific research efforts have been made in the areas of nanoporous materials and nano adsorbents [7].

Nanostructures, nanoparticles, nanocomposites and nanocrystalline materials are of interest for both fundamental scientific research and technological applications since some of their properties are controlled by their extremely large surface areas [8]. Furthermore, scientists are still targeting new adsorbent with good property. In recent years, with the development of nanotechnology, various nanomaterials have been extensively used in adsorption [9]. The removal of nanosized adsorbents is an important issue and requires high cost. The application of magnetic particles have been proposed as an approach to imparting magnetic properties onto adsorbents [10], which can be separated from treated water by a simple magnetic process. Ferriferous salts particles have become the most popular magnetic material due to its low cost, low toxicity and eco-friendliness [11].

NZVI particle technology becoming a popular choice for treatment of hazardous and toxic wastes, and for remediation of contaminated sites [12]. In the past few years, large numbers of research works have been emerged focusing on production of more active and stable NZVIparticles. On the other hand, simplification of the synthetic procedure of the nano adsorbents, will reduce the cost and increase the simulating ,these important factor for their utilization in large-scale applications [13]. However, most synthetic NZVI procedures display a significant disadvantage such as the observed aggregation, which decreased the activity of NZVI. For this reason, the modification and stabilization of NZVI in solid matrices like MSNs followed by their good dispersion which can lead to steady or even enhanced remediation ability was deemed necessary [16]. Therefore, supported NZVI showed a higher activity compared to non-supported systems. The nano-porous matrices may additionally affect the catalytic and sorption properties of the hosted nano particles [17].

Previously, the study of MB adsorption onto NZVI/MSNs has been conducted as reported by Hammed et al. [18]. However, the study did not include the kinetic and thermodynamic parameter of the adsorption, that are important to determine the rate of removal of MB from aqueous solution and to characterize the nature of the adsorption process (e.g. spontaneity). In this work, the fume silica was activated for the preparation of MSN, followed by impregnation of the ferric chloride hexahydrate $\left(\mathrm{FeCl}_{3} .6 \mathrm{H}_{2} \mathrm{O}\right)$ on MSN. Due to the high surface area to volume ratio of the prepared adsorbent NZVI/MSNs, than that of the NZVI, which exhibits an enhanced reactivity and thus activated and increased the uptake capacity of MB through their depletion in neutral conditions. NVZI/MSN nano composite was used as highly efficient adsorbent with excellent separation properties. Methylene blue (MB) was selected as model pollutant to evaluate the optimum adsorption condition included contact time, initial $\mathrm{pH}$ solution, isotherm studies and temperature under laboratory conditions. The kinetic and thermodynamic parameter has been investigated for adsorption of MB onto NZVI/MSNs. Pseudo-first and second order kinetic models were used to be fitted with experimental data. Thermodynamic parameters such as changes of enthalpy, entropy and Gibb's free energy were included in this study. Other studies of adsorption of MB onto NZVI/MSNs includes equilibrium time, $\mathrm{pH}$ effect and adsorption isotherm model has been reported previously [19].

\section{Materials and Methods}

\subsection{Materials}

Sodium borohydride $\left(\mathrm{NaBH}_{4}\right)$ 98.5\%, iron(III) chloridehexahydrate $\left(\mathrm{FeCl}_{3} .6 \mathrm{H}_{2} \mathrm{O}\right)$, methylene blue (MB, indicator grade) were obtained from Merck, with molecular weight of $373.9 \mathrm{~g} / \mathrm{mol}$ and formula of $\mathrm{C}_{16} \mathrm{H}_{18} \mathrm{~N}_{3} \mathrm{SCl}$, while fumed silica (micro porous silica, with a median particle size of $2.5 \mu \mathrm{m}$ )with purity $99 \%$, was obtained from Dongyang Chemical Company and used directly. Sodium hydroxide $(\mathrm{NaOH})$ and hydrochloric acid $(\mathrm{HCl})$ with purity $99 \%$, 
were obtained from Sigma-Aldrich. Absolute ethanol and acetone (analytical grade) were purchased from Merck and used without purification. The dye stock solution was prepared by dissolving accurately weighted MB in distilled water to the concentration of 500 $\mathrm{mg} / \mathrm{L}$. The experimental solutions were obtained by diluting the dye stock solution in accurate proportions to required initial concentrations of MB solution.

A spectrophotometer type (GENESYS 10S UV-VIS) was used for the determination of absorbance at the predetermined maximum absorbance wavelength $\left(\lambda_{\max }\right.$ of $\left.663 \mathrm{~nm}\right)$ of (MB). Different concentrations of MB subsequently were used.

\subsection{Synthesis of NZVI/MSNS}

NZVI particles were prepared by using liquid phase reduction methods as described elsewhere [12]. $\mathrm{FeCl}_{3}(2 \mathrm{M})$ solution was prepared by dissolving $\mathrm{FeCl}_{3} \cdot 6 \mathrm{H}_{2} \mathrm{O}$ into mixture of ethanol and distilled water $(3: 1 \mathrm{v} / \mathrm{v})$. $\mathrm{NaBH}_{4}$ solution was prepared by dissolving one gram of $\mathrm{NaBH}_{4}$ in $25 \mathrm{~mL}$ distilled water. Reduction of $\mathrm{FeCl}_{3}$ solution was conducted by adding $\mathrm{NaBH}_{4}$ solution drop by drop under the vigorous stirring until the mixture's color turned from brown to black [20]. Excess $\left(\mathrm{NaBH}_{4}\right)$ was typically applied in order to accelerate the reaction and ensured uniform growth of iron particles. Ferric iron ion $\left(\mathrm{Fe}^{+3}\right)$ was reduced and NZVI particles precipitated instantly according to Equation (1).

$$
\begin{gathered}
4 \mathrm{Fe}^{+3}+3 \mathrm{BH}^{4-}+9 \mathrm{H}_{2} \mathrm{O} \rightarrow 4 \mathrm{FeO}(\mathrm{s}) \\
+3 \mathrm{H}_{2} \mathrm{BO}_{3^{-}}(\mathrm{aq})+12 \mathrm{H}^{+}+6 \mathrm{H}_{2}
\end{gathered}
$$

MSNS was prepared by dissolved three grams of fumed silica in $50 \mathrm{~mL}$ concentrated hydrochloric acid and refluxed for 3 hours at 90 ${ }^{\circ} \mathrm{C}$. The solution was left at room temperature $\left(27 \pm 2{ }^{\circ} \mathrm{C}\right)$ for overnight then the filtrate was separated from the solution by using filter paper. Excess $\mathrm{HCl}$ was removed from filtrate by washing with deionized water several times until $\mathrm{pH}$ value of 7 was achieved. Washed MSNS was dried in oven at $150{ }^{\circ} \mathrm{C}$ for 4 hours, and then kept in desiccator prior further utilization.

In order to prepare NZVI/MSNS, one $\mathrm{g}$ of MSNS was mixed with $0.4 \mathrm{~g} \mathrm{FeCl}_{3} \cdot 6 \mathrm{H}_{2} \mathrm{O}$. The solid then was diluted using $100 \mathrm{~mL}$ mixture of ethanol and deionized water $(3: 1 \mathrm{v} / \mathrm{v})$. Twenty five $\mathrm{mL}$ of $\mathrm{NaBH}_{4}$ solution $(20 \mathrm{~g} / \mathrm{L})$ was added into the ferric chloride-MSNS mixture drop by drop to reduce Fe. After 30 minutes of agitation, the solid NZVI/MSNS were formed. The solids were collected by filtration and washed with acetone for three times. Remaining solids was dried at $60{ }^{\circ} \mathrm{C}$ under vacuum to remove the excess acetone and moisture.

\subsection{Characterization of adsorbent}

The surface area of adsorbent was determined from the adsorption isotherms of nitrogen at $-196{ }^{\circ} \mathrm{C}$ onto the catalyst using Micromeritics ASAP 2000. All the samples were degassed at $105{ }^{\circ} \mathrm{C}$ prior to the analysis and the adsorption of $\mathrm{N}_{2}$ was measured at -196 ${ }^{\circ} \mathrm{C}$. Brunauer-Emmett-Teller (BET) equation was employed to calculate the specific surface area. The diffractogram of adsorbents were obtained by a Rigakumini Flex II desktop X-ray diffractometer with $\mathrm{Cu} \mathrm{Ka}$ as a source at a tube voltage of $30 \mathrm{kV}$ and a current of $15 \mathrm{~mA}$. The diffractogram patterns were collected in $2 \theta$ range from $0^{\circ}$ to $80^{\circ}$ with step sizes of $0.02^{\circ}$ and at a scanning speed of $1 \% \mathrm{~min}$. The surface structure and elemental analysis of adsorbent was observed by using FESEM/EDX (JEOL). FTIR spectra were collected by using PerkinElmer Spectrometry 100.

\subsection{Adsorption studies}

Adsorption of MB onto NZVI/MSNS was conducted in batch experiment. $250 \mathrm{~mL}$ conical flasks were filled up with $100 \mathrm{~mL}$ of $\mathrm{MB}$ solution at desired initial concentration. Amount of $100 \mathrm{mg}$ adsorbent was loaded into the flasks and then sealed with rubber cork and aluminum foil. The flasks were put on a rotary shaker, set to $150 \mathrm{rpm}$ speed at room temperature during the experiment period entirely. Initial and final concentrations of MB in solution were determined by usinga Genesys $10 \mathrm{~S} \mathrm{UV}-\mathrm{Vis}$ spectrophotometer based on the absorbance at $\lambda_{\max }$ of $663 \mathrm{~nm}$. Adsorption capacity $\left(q_{e}\right)$ of the adsorbent was calculated by following Equation (2) [21].

$$
q_{e}=\frac{\left(C_{o}-C_{e}\right) V}{W}
$$

where $C_{o}$ and $C_{e}$ are $\mathrm{MB}$ concentration in $\mathrm{mg} / \mathrm{L}$ at initial and at given time, respectively. $V$ is the volume of MB solution in L, while $W$ is the weight of adsorbent (g). Equilibrium time of the adsorption has been determined by varying the contact time of the adsorption at 2, 4, 8, 16, 30, 60,90 and $180 \mathrm{~min}$. The equilibrium is 
achieved when the MB concentration in aqueous solution is remained constant. Langmuir and Freundlich isotherm models were employed to investigate the adsorption isotherm of MB onto adsorbents.

Kinetic study of adsorption was conducted by varying the contact time of the adsorption. Pseudo first order kinetic model was evaluated by plotting the correlation between $\ln \left(q_{e}-q_{t}\right)$ and time (t) according to the Equation (3). Equation (4) shows the linearization of $\left(t / q_{t}\right)=$ $f(t)$. Reaction rate constant $k_{1}$ and $k_{2}$ can be determined by the plot's slope for first order as well as its intercept for second order kinetic model.

$$
\begin{aligned}
& \ln \left(q_{e}-q_{t}\right)=\ln q_{e}-k_{1} t \\
& \frac{t}{q_{t}}=\frac{1}{k_{2} q_{e}}+\frac{t}{q_{e}}
\end{aligned}
$$

Thermodynamic parameters of adsorption processes were examined by conducting the adsorption in various temperatures. $\Delta \mathrm{H}^{\circ}, \Delta \mathrm{S}^{\circ}$, and $\Delta \mathrm{G}^{\circ}$ of adsorption were determined by correlating the distribution coefficient of the adsorption $\left(K_{d}=q_{e} / C_{e}\right)$ and the temperature of the adsorption (T, K). $\Delta G^{\circ}, \Delta H^{\circ}$ and $\Delta S^{\circ}$ for the adsorption process can be expressed in Equation (5). From second law of thermodynamic, the Gibbs free energy is defined in Equation (6).

$$
\begin{aligned}
& \Delta G^{\circ}=-R T \ln K_{d} \\
& \Delta G^{\circ}=\Delta H^{\circ}-T \cdot \Delta S^{\circ}
\end{aligned}
$$

Substitution of Equation (5) to Equation (6) results:

$$
\ln K_{d}=\frac{-\Delta H^{o}}{R T}+\frac{\Delta S^{o}}{R}
$$

where $R$ is the ideal gas constant $\left(\mathrm{kJ} \mathrm{mol}^{-1} \mathrm{~K}^{-1}\right)$, $T$ is temperature in $\mathrm{K}$, and $K_{d}$ is the equilibrium constant equals to $q_{e} / C_{e}$. The enthalpy change and the entropy change can be calculated from a plot of $\ln K_{d}$ vs $1 / T$.

\section{Results and Discussion}

\subsection{Adsorbent characterization}

BET surface area and pore volume of adsorbents is tabulated in Table 1. Small surface area of $41 \mathrm{~m}^{2} / \mathrm{g}$ was provided by NZVI, while a larger surface area of $126 \mathrm{~m}^{2} / \mathrm{g}$ was generated by MSNS. BET surface area of NZVI/MSNS was observed decreasing compare to that of MSNS with the value of $72 \mathrm{~m}^{2} / \mathrm{g}$. It was due to the particles of NZVI filled the pore and spread on the MSNS surface. However, the surface area of NZVI/MSNS was still larger than that of NZVI standalone. Same phenomenon was also observed in pore size of adsorbent, where the pore volume of NZVI/MSNS $\left(0.466 \mathrm{~cm}^{3} / \mathrm{g}\right)$ was smaller than that of MSNS $\left(1.051 \mathrm{~cm}^{3} / \mathrm{g}\right)$ but larger than that of NZVI $\left(0.165 \mathrm{~cm}^{3} / \mathrm{g}\right)$.

Diffractogram of NZVI and NZVI/MSNS are shown in Figure 1. The NZVI without iron oxides was identified by the XRD spectrometer under alkaline conditions. No obvious reflections of $\mathrm{Fe}$ oxides were observed in the XRD pattern of prepared NZVI suggesting that their major surface species are $\mathrm{Fe}^{0}$. The XRD pattern of NZVI/MSNS indicates the crystalline nature (iron, silicon) of NZVI/MSNs, which was caused by the impregnation of iron nanoparticles $(2,2,2)$ and $(2,0,0)$ [5, 16]. This result indicates that the NZVI/MSNs that the pattern clearly displaced, the higher order $(2,2,2)$ and $(2,0,0)$ reflections suggesting that the hexagonal structure of the support matrix and the nanoparticle growth on its surfaces. Due to the low content of NZVI, obvious diffraction peaks are observed at the $2 \theta$ of $35.07^{\circ}, 53.89^{\circ}$ and $31.59^{\circ}$. According to Petala et al., these small peaks suggests that NZVI was partially oxidized to $\mathrm{Fe}_{2} \mathrm{O}_{3}$ or $\mathrm{Fe}_{3} \mathrm{O}_{4}$ [22].

Figure $2 \mathrm{a}$ and $2 \mathrm{~b}$ illustrates the FESEM image of NZVI and NZVI/MSNS, respectively. In Figure 2a, it is observed that NZVI particles tend to form a chain-like aggregate. According to Park et al. [23] and Noubactep et al. [24], these structure is formed due to the magnetic attractive force between particles. Figure $2 \mathrm{~b}$ shows NZVI particles filled up the pore and

Table 1. Surface area and pore volume of adsorbents

\begin{tabular}{ccc}
\hline Adsorbent & BET surface area, $\mathrm{m}^{2} / \mathrm{g}$ & BJH pore volume, $\mathrm{cm}^{3} / \mathrm{g}$ \\
\hline NZVI & 41 & 0.165 \\
MSNS & 126 & 1.051 \\
NZVI/MSNS & 72 & 0.466 \\
\hline
\end{tabular}


spread on the surface of MSNS. EDX results indicate the presence of $\mathrm{Fe}$ in NZVI/MSNS as shown in Table 2. It confirmed the XRD results above mentioned.

FTIR spectra of adsorbents are illustrated in Figure 3. Infrared spectrum of MSNS (b) shows peaks at wavenumbers of 1680,1236 , 1108, 817 and $480 \mathrm{~cm}^{-1}$. The bands may be assigned to characteristic vibration of $\mathrm{Si}-\mathrm{O}-\mathrm{Si}$ bridges cross linking the silicate network [18, 19]. The strong band at $1236 \mathrm{~cm}^{-1}$ and 1108 $\mathrm{cm}^{-1}$ can be assigned to the asymmetric

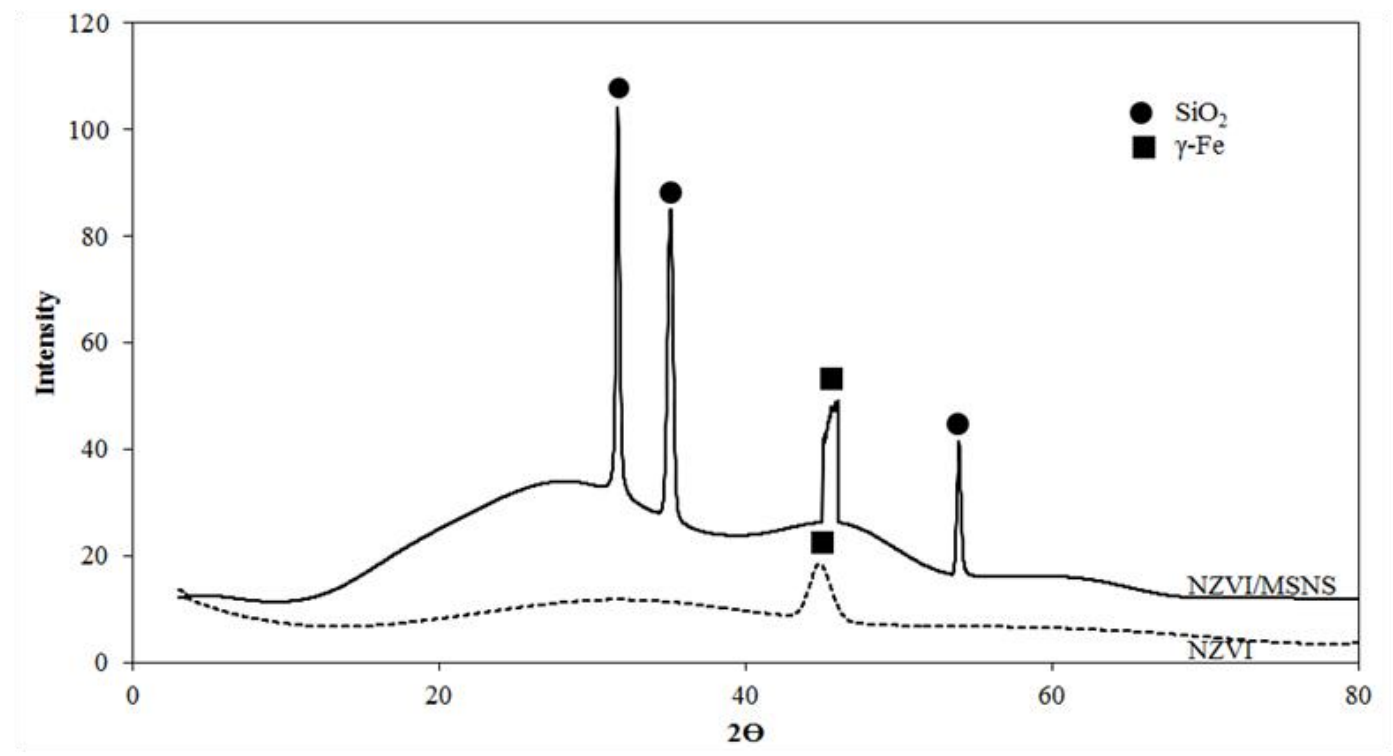

Figure 1. Diffractogram of NZVI and NZVI/MSNS

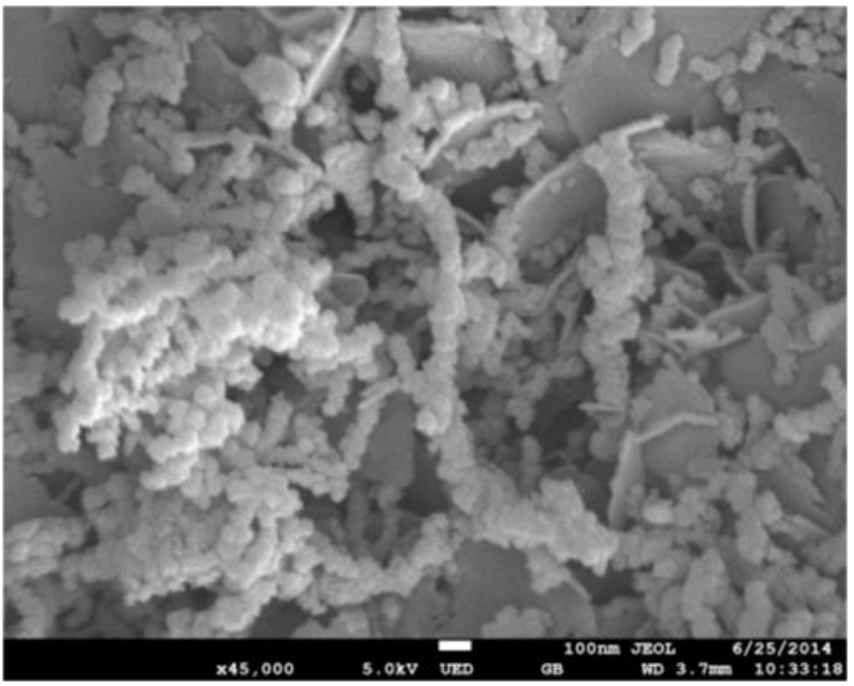

(a)

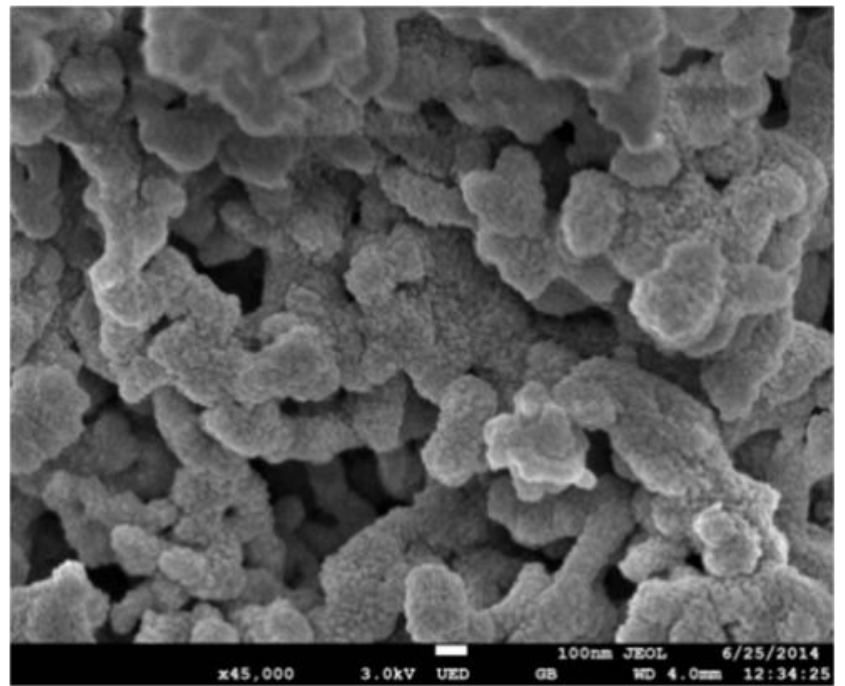

(b)

Figure 2. FESEM micrograph of (a) NZVI, and (b) NZVI/MSNS

Table 2. Elemental analysis of adsorbents by EDX

\begin{tabular}{ccccc}
\hline \multirow{2}{*}{ Element } & \multicolumn{2}{c}{ MSNS } & \multicolumn{2}{c}{ NZVI/MSNS } \\
\cline { 2 - 5 } & \% weight & \% atomic & \% weight & \% atomic \\
\hline $\mathrm{O}$ & 59.15 & 71.76 & 62.57 & 75.56 \\
$\mathrm{Si}$ & 40.85 & 28.24 & 33.61 & 23.12 \\
$\mathrm{Fe}$ & - & - & 3.82 & 1.32 \\
Total & 100.00 & 100.00 & 100.00 & 100.00 \\
\hline
\end{tabular}



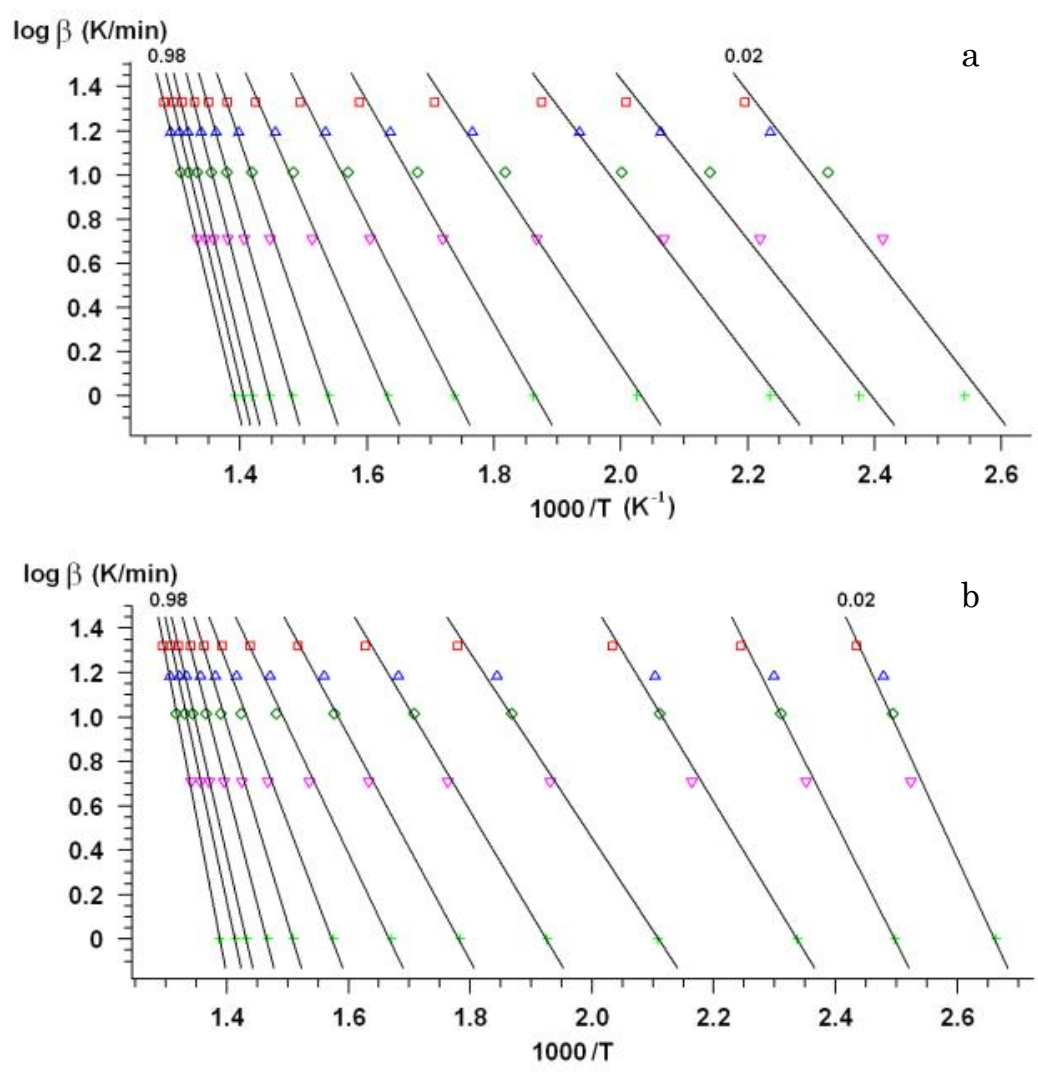

Figure 5. The samples weight loss rates in the coordinates log $d a / d t-1000 / T$, obtained using OzawaFlynn-Wall method: a - non catalytic; b - with $\mathrm{CoCl}_{2} 5 \%$ (wt.)
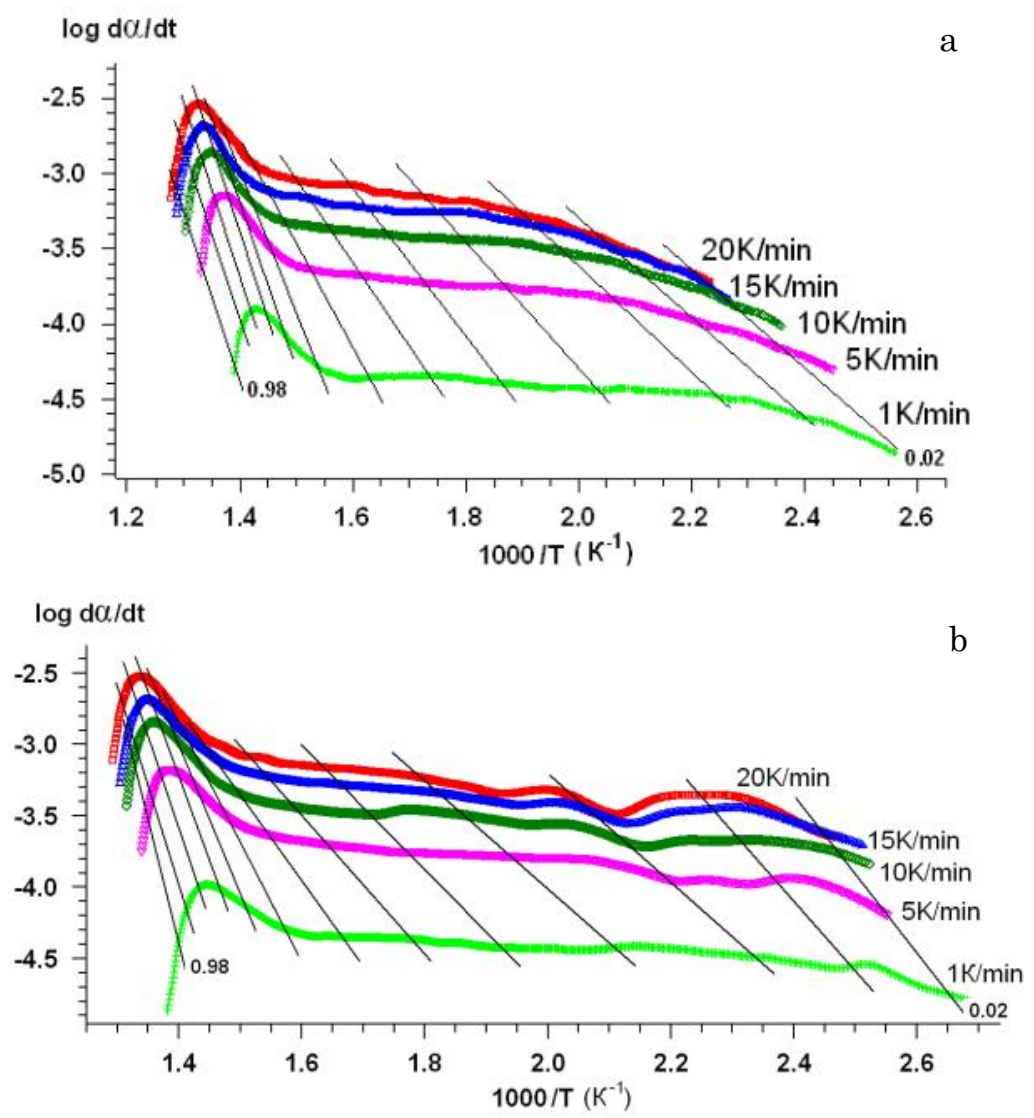

Figure 6. The samples weight loss rate in the coordinates log $d a / d t-1000 / T$, obtained using Friedman method: a - non catalytic; b - with $\mathrm{CoCl}_{2} 5 \%$ (wt.) 
stretching mode vibration of $\mathrm{Si}-\mathrm{O}-\mathrm{Si}$ groups [25], while the band at 817 and $480 \mathrm{~cm}^{-1}$ may be attributed to bending motion of oxygen and rocking motion of bridging oxygen perpendicular to $\mathrm{Si}-\mathrm{O}-\mathrm{Si}$ plane respectively [26]. Obvious reduction of the peak heights are observed in the infrared spectrum of NZVI/MSNS (a). This may be attributed to the formation of $\mathrm{Si}-\mathrm{O}-\mathrm{Fe}$ bonds. Furthermore, the broad adsorption band between $1420 \mathrm{~cm}^{-1}$ and $1360 \mathrm{~cm}^{-1}$ can be correlate with the presence of borate species produced during NZVI synthesis [27].

\subsection{Adsorption study}

Figure 4 illustrates the concentration of MB in aqueous solution as function of adsorption contact time. Concentration of MB was rapidly decreased in first 10 minutes. The decreasing of MB concentration was slower after $10 \mathrm{~min}$ utes, before the concentration remained constant at equilibrium time. As seen in Figure 4, equilibrium time has been achieved at contact time of 60 minutes. At equilibrium, total $\mathrm{MB}$ adsorbed by NZVI, MSNS and NZVI/MSNS were $6.261 \mathrm{mg} / \mathrm{g}, 8.658 \mathrm{mg} / \mathrm{g}$ and $17.601 \mathrm{mg} / \mathrm{g}$, respectively. It can be concluded that support-

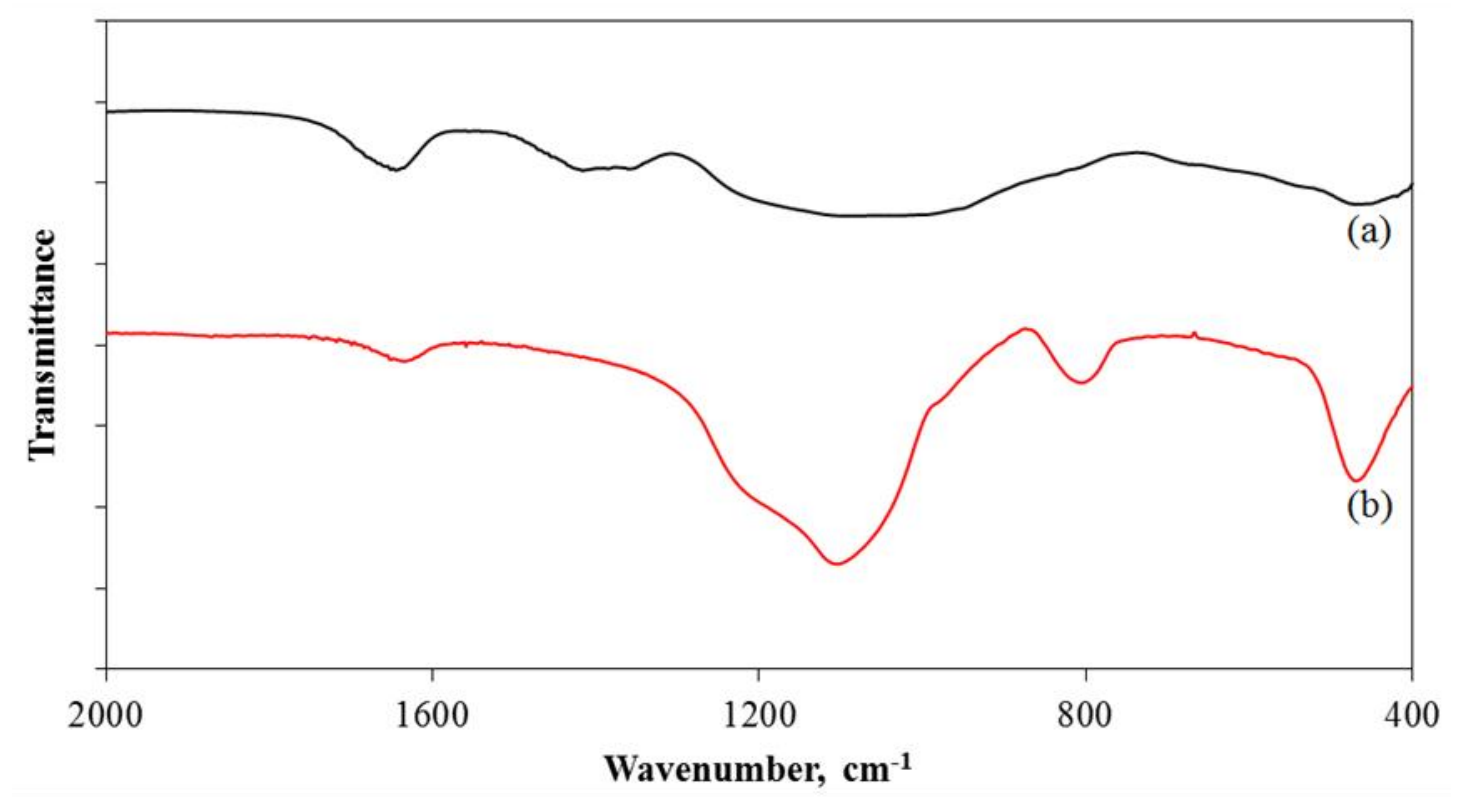

Figure 3. Infrared spectra of NZVI/MSNS (a) and MSNS (b)

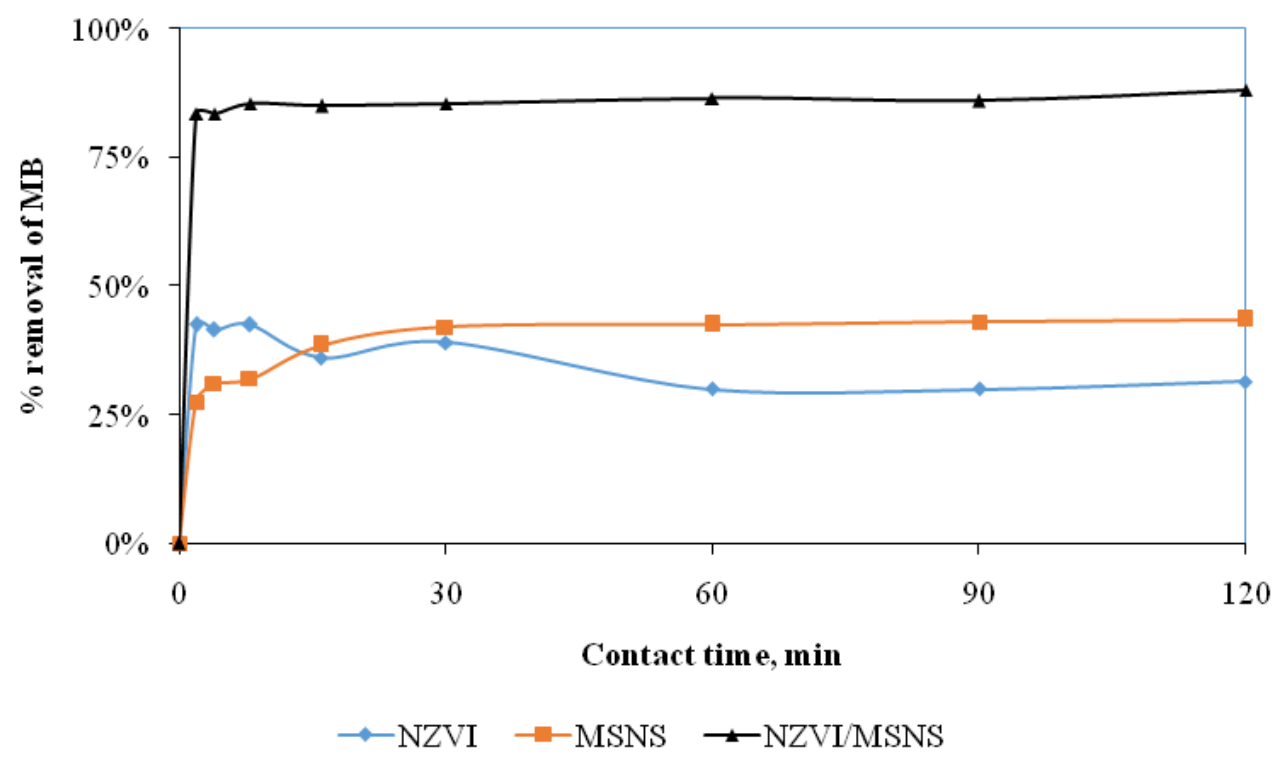

Figure 4. Effect of contact time on concentration of $\mathrm{MB}$ in aqueous solution 
ing NZVI by MSNS drastically increase the adsorption capacity compare to that of NZVI or MSNS alone. This result also indicates that adsorption capacity is dependent with surface area and pore volume of adsorbents as shown in Table 1. In addition, dispersion of NZVI onto the support as shown in FESEM image provided significant contribution in enhancing the adsorption performance.

Langmuir and Freundlich isotherm models were employed to describe the adsorption process in this study. Langmuir isotherm is based on the assumption that adsorption on a homogenous surface, the surface consist of identical sites, equally available for adsorption and with equal energies of adsorption and that the adsorbent is saturated after one layer of adsorbate molecules forms onto surface [28, 29]. Equation (8) expressed the linearized form of Langmuir adsorption isotherm. The Langmuir constant, $K_{L}$ and $q_{m}$ can be calculated from plot $C_{e} / q_{e}$ versus $C_{e}$ as illustrated in Figure 5a.

$$
\frac{C_{e}}{q_{e}}=\frac{1}{K_{L} q_{m}}+\frac{C_{e}}{q_{m}}
$$

The linearized Freundlich isotherm equation that corresponds to the adsorption on heterogeneous surface is given as Equation (9). $\ln q_{e}=\ln K_{F}+\frac{1}{n} \ln C_{e}$

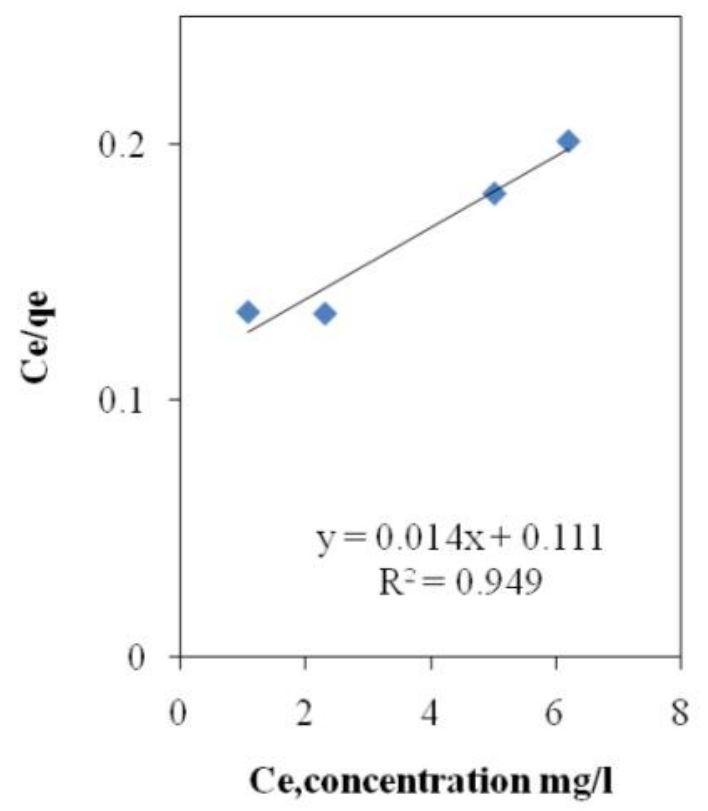

(a) where $C_{e}$ is the concentration of solute at equilibrium $(\mathrm{mg} / \mathrm{L})$ and $q_{e}$ is the adsorption capacity at equilibrium $(\mathrm{mg} / \mathrm{g})$. The Freundlich isotherm constants $K_{F}$ and $n$ can be determinate from the plot of $\ln q_{e}$ versus $\ln C_{e}$ as illustrated in Figure 5b. The slope 1/n measures the surface heterogeneity. Heterogeneity becomes more prevalent as $1 / n$ gets closer to zero [25].

Langmuir and Freundlich isotherm parameters for adsorption of MB onto NZVI/MSNS are summarized in Table 3. Langmuir and Freundlich constant of adsorption of MB onto NZVI/MSNS were $0.125 \mathrm{~L} / \mathrm{mg}$ and 1.594 , respectively. Maximum adsorption capacity of MB onto NZVI/MSNS determined by Langmuir isotherm was $71.42 \mathrm{mg} / \mathrm{g}$. This value is comparable with some other adsorbent as shown in Table 2. In overall, Freundlich isotherm characterized the adsorption process better than that of Langmuir isotherm as indicated by higher correlation coefficient value. The surface heterogeneity of the adsorbent became more prevalent, since the $1 / \mathrm{n}$ value of Freundlich isotherm parameter of adsorption was nearly zero [25]. Hence, the adsorption of MB onto NZVI/MSNS can be considered as a multilayer adsorption rather than a monolayer adsorption.

\subsection{Kinetic Study}

Plot of both first and second order kinetic models are illustrated in Figure 6, while the kinetic parameters calculated were summarized

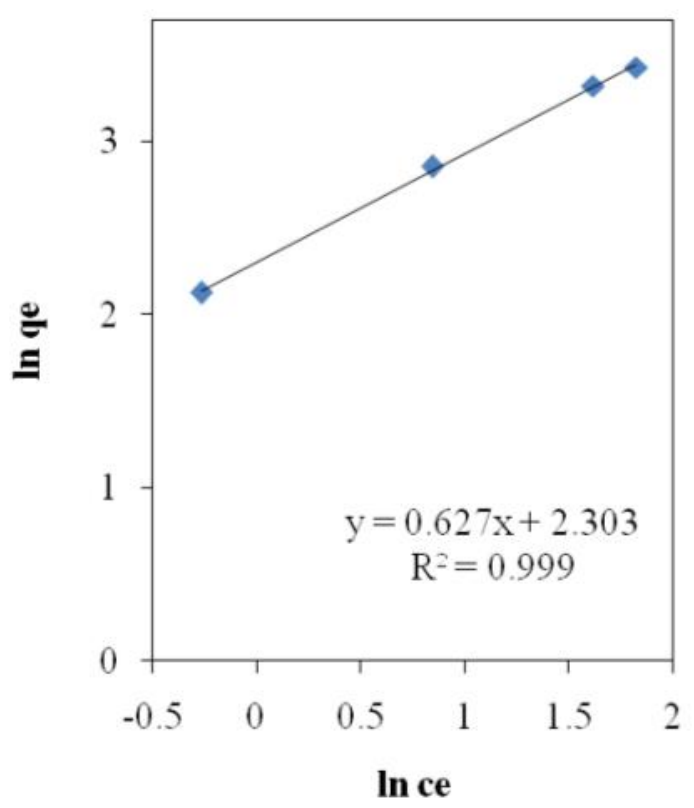

(b)

Figure 5. Linearization of adsorption isotherm plot for (a) Langmuir, and (b) Freundlich model 


\section{Bulletin of Chemical Reaction Engineering \& Catalysis, 11 (1), 2016, 258}

Table 3. Isotherm parameters of the adsorption of MB onto NZVI/MSNs and for selected adsorbents.

\begin{tabular}{lccccccc}
\hline \multirow{2}{*}{\multicolumn{1}{c}{ Absorbent }} & \multicolumn{3}{c}{ Langmuir } & \multicolumn{3}{c}{ Freundlich } & \multirow{2}{*}{ Ref. } \\
\cline { 2 - 7 } & $K_{\mathrm{Ll} / \mathrm{mg}}$ & $Q_{\max }$ & $\mathrm{R}^{2}$ & $K_{F}$ & $1 / N$ & $\mathrm{R}^{2}$ & \\
\hline NZVI/MSNs & 0.125 & 71.42 & 0.9502 & 1.594 & 0.099 & 0.9991 & This study \\
Date palm leaves & 0.006 & 43.103 & 0.9510 & 0.541 & 0.725 & 0.9540 & {$[26]$} \\
Cellolignin & 0.07 & 95.23 & 0.9951 & 8.95 & 0.60 & 0.9856 & {$[15]$} \\
Modified pumice stone & 0.132 & 15.87 & 0.992 & 3.45 & 0.45 & 0.999 & {$[27]$} \\
Low-Cost Natural Jor- & 0.026 & 16.6 & 0.9999 & 9.98 & 0.11 & 0.8746 & {$[28]$} \\
danian Tripoli & & & & & & & \\
CMCD-MNP & 0.01 & 138.9 & 0.998 & 120.60 & 0.33 & 0.957 & {$[2]$} \\
Treated iron filings & 0.324 & 27.933 & 0.9952 & 6.979 & 0.429 & 0.9636 & {$[14]$} \\
Montmorillonite & 61 & 6.760 & 0.999 & 0.0061 & 0.300 & 0.881 & {$[3]$} \\
$\mathrm{Co}_{3} \mathrm{O}_{4} / \mathrm{SiO}_{2}$ & 8.39 & 53.87 & 0.951 & 587.89 & 1.230 & 0.999 & {$[29]$} \\
\hline
\end{tabular}

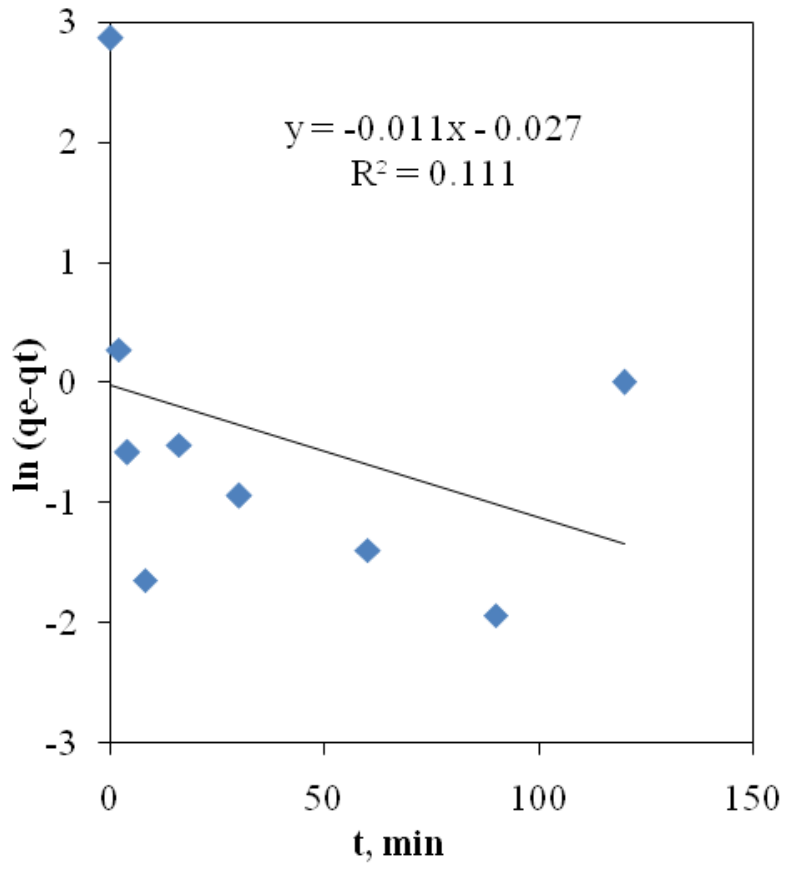

(a)

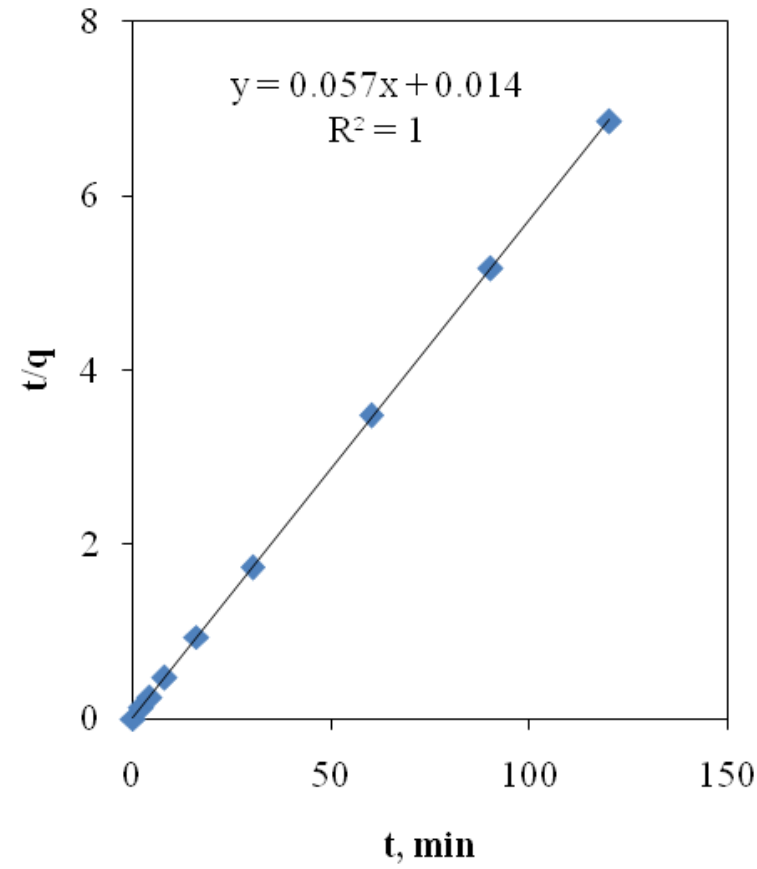

(b)

Figure 6. Linear plot of pseudo first (a) and second (b) order kinetic model of adsorption of MB onto NZVI/MSNS.

Table 4. Kinetic parameters of the adsorption of MB onto NZVI/MSNs and other selected adsorbents.

\begin{tabular}{lccc}
\hline \multicolumn{1}{c}{ Adsorbent } & $k_{2}, \mathrm{~g} / \mathrm{mg} . \mathrm{min}$ & $q_{e}, \mathrm{mg} / \mathrm{g}$ & Ref. \\
\hline NZVI/MSNs & 0.218 & 17.513 & This study \\
Date palm leaves & 0.0032 & 15.152 & {$[26]$} \\
Mesoporous silica & 0.0084 & 11.24 & {$[11]$} \\
Low-Cost Natural Jordanian Tripoli & 0.026 & 9.76 & {$[28]$} \\
Crofton weed stalk (CWS) & 0.0120 & 17.575 & {$[22]$} \\
\hline
\end{tabular}


in Table 4. Linear regression of both models provided the correlation coefficient value of 0.11 and 1.00 for pseudo first order and second order, respectively. It is obviously clear that the adsorption kinetic of $\mathrm{MB}$ onto NZVI/MSNS obeys the pseudo second order kinetic model. This result is also in agreement with other adsorbent that were fitted best by pseudo second order model as shown in Table 4.

\subsection{Thermodynamic study}

Effect of temperature on adsorption properties of MB onto NZVI/MSNS can be illustrated by using van't Hoff plot that correlates between $1 / T$ and $\ln K_{d}$ as shown in Figure 7. From this linear plot, thermodynamics properties such as $\Delta H^{\circ}, \Delta S^{\circ}$ and $\Delta G^{\circ}$ were determined according to Equation (5) and (6). The results are summarized in Table 5. Positive change of

Table 5. Thermodynamics parameters of adsorption of MB onto NZVI/MSNS

\begin{tabular}{|c|c|}
\hline Parameters, unit & Value \\
\hline$\Delta \mathrm{H}^{\circ}, \mathrm{kJ} / \mathrm{mol}$ & 90.53 \\
\hline$\Delta \mathrm{S}^{\circ}, \mathrm{J} / \mathrm{mol} . \mathrm{K}$ & 300.17 \\
\hline \multicolumn{2}{|l|}{$\Delta \mathrm{G}^{\circ}, \mathrm{kJ} / \mathrm{mol}$} \\
\hline $303 \mathrm{~K}$ & -0.42 \\
\hline $308 \mathrm{~K}$ & -1.92 \\
\hline $313 \mathrm{~K}$ & -3.42 \\
\hline $318 \mathrm{~K}$ & -4.92 \\
\hline $323 \mathrm{~K}$ & -6.42 \\
\hline
\end{tabular}

enthalpy of adsorption indicates that the process is endothermic. It is in agreement with the increasing of adsorption uptake at higher adsorption temperature. The positive value of $\Delta S^{\circ}$ showed the affinity of the NZVI/MSNs for $\mathrm{MB}$ and the increasing randomness at the solid-solution interface during the adsorption process. The negative value of $\Delta G^{\circ}$ indicated the feasibility of the process and the spontaneous nature of the adsorption with a high preference of MB onto NZVI/MSNs. The values of $\Delta G^{\circ}$ were found to decrease as the temperature increased, indicating less driving force and hence resulting in less adsorption capacity [30]. Observed thermodynamic parameters indicate that the process was spontaneous and endothermic.

\section{Conclusions}

NZVI/MSNS, a new adsorbent, has been successfully prepared by reduction method with high surface area and high adsorption capacity which determine by the isotherm studies. The adsorbent has large surface area and pore size of $72 \mathrm{~m}^{2} / \mathrm{g}$ and $0.466 \mathrm{~cm}^{3} / \mathrm{g}$, respectively. FESEM micrograph of adsorbent indicated the size of NZVI particle was within the range of 7-10 $\mathrm{nm}$. Adsorption study of $\mathrm{MB}$ onto NZVI/MSNS showed good performance with maximum adsorption capacity is 71.42 $\mathrm{mg} / \mathrm{g}$. Adsorption process is considered as multilayer adsorption and fit to the Freundlich

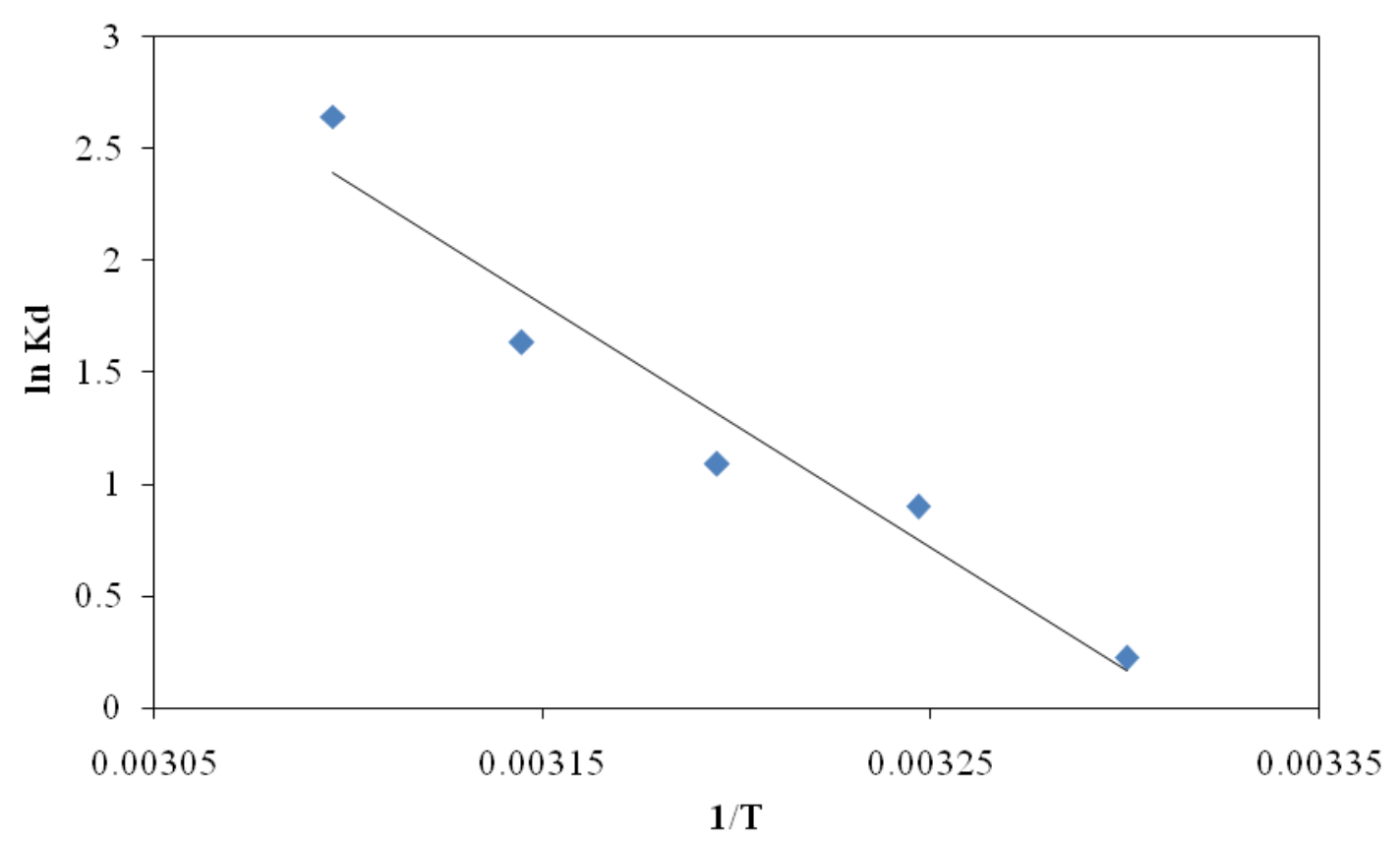

Figure 7. van't Hoff plot of effect of temperature on adsorption properties of MB onto NZVI/MSNS 
isotherm models. Thermodynamically, adsorption of NZVI/MSNS is endothermic with $\Delta H^{\circ}$ value is $90.53 \mathrm{~kJ} / \mathrm{mol}$. Value of $\Delta S^{\circ}(300.17$ $\mathrm{J} / \mathrm{mol} . \mathrm{K})$ and $\Delta G^{\circ}(-1.92$ to $-6.42 \mathrm{~kJ} / \mathrm{mol})$ indicates the spontaneity of the adsorption in nature. In conclusion, NZVI/MSNS exhibit good performance in adsorption of methylene blue and can be considered as promising adsorbent to be applied in industrial waste water remediation.

\section{Acknowledgement}

The financial support by UMP Postgraduate Research Grant no. GRS 140374 for this research is gratefully acknowledged.

\section{References}

[1] Sarioglu, M., Atay, U.A. (2006). Removal of methylene blue by using bio solid. Global NEST Journal, 8 (2): 113-120.

[2] Badruddoza, A., Goh, S., Hidajat, K. Uddin, M., (2010). Synthesis of carboxymethyl-cyclodextrin conjugated magnetic nanoadsorbent for removal of methylene blue. Colloids and Surfaces A: Physicochemical and Engineering Aspects, 367(1-3): 85-95.

[3] Fail, A.B., Ozmetin, C., Korkmaz, M. (2012) . Cationic dye (methylene blue) removal from aqueous solution by montrmorillonite. Bull. Korean Chem. Soc., 33(10): 3184-3190

[4] Oyelude, E.O., Takyi, F.A., Felix, A. (2012). Removal of methylene blue from aqueous solution using alkali modified malted sorghum mash. Turkish Journal of Engineering and Environmental Science. 6: 161-169.

[5] Kadirova, Z.C., Katsumata, K., Isobe, T., Matsushita, N., Nakajima, A., Okada, K. (2013). Adsorption and Photodegradation of Methylene blue by iron oxide impregnated on granular activated carbons in an oxalate solution. Applied Surface Science 284: 72-79.

[6] Petala, E., Dimos, K., Douvalis, A., Bakas, T., Tucek, J., Zboril, R., Karakassides, M.A. (2013). Nano Scale Zero-Valent Iron Supported on Mesoporous Silica: Characterization and Reactivity for $\mathrm{Cr}(\mathrm{VI})$ Removal from Aqueous Solution. Journal of Hazardous Materials, 216 (2): 295-306.

[7] Sun, X., Yan, Y., Li, J., Hana, W., Wang, L., (2014). Nanoscale Zero-Valent iron Particles for chromium(VI) removal from groundwater: Mechanism, effect of $\mathrm{pH}$, humic acid and sustained reactivity. Journal of Hazard materials 12: 26-33.

[8] Frost, R.L., Xi, Y., He, H. (2013). Synthesis, Characterization of Palygorskite Supported
Zero-Valent Iron and Its Application for Methylene Blue Adsorption. Journal of Colloid and Interface Science, 341: 153-161.

[9] Tan, I.A.W., Ahmad, A.L., Hameed, B.H. (2008). Adsorption of Basic Dye on HighSurface-Area Activated Carbon Prepared from Coconut Husk: Equilibrium, Kinetic and Thermodynamic Studies. Journal of Hazardous Materials, 154(1-3): 337-346.

[10] Shih, Y.H., Tso, C.P., Tung, L.Y. (2010). Rapid degradation of methyl orange with nano scale zero valent iron particles. J. Environ. Eng. Manage., 20(3): 137-143.

[11] Kareem, S.H., Ali, I.H., Jalhoom, M.G. (2014). Synthesis and Characterization of Organic Functionalized Mesoporous Silica and Evaluate their Adsorptive Behavior for Removal of Methylene Blue from Aqueous Solution. American Journal of Environmental Sciences, 10(1): 48-60.

[12] Rahman, M.A., Amin, S.M.R., Alam, A.M.S. (2012). Removal of Methylene Blue from Waste Water Using Activated Carbon Prepared from rice husk. Dhaka Univ. Journal of Science. 60(2): 185-189.

[13] Ho, Y., Malarvizhi, R., Sulochana, N. (2009). Equilibrium Isotherm Studies of Methylene Blue Adsorption onto Activated Carbon Prepared from Delonixregia Pods. Journal of Environmental Protection Science, 3: 111-116.

[14] Muslim, M.A., Hammoud, Z.A. (2014). Removal of Methylene Blue from Aqueous Solution by using iron filings waste material in batch and continuous experiments. Journal of Babylon University/Engineering Sciences. 22 (1): $35-45$.

[15] Suteu, D., Malutan, T. (2013). Industrial Cellolignin Wastes as Adsorbent for Removal of Methylene Blue Dye from Aqueous Solutions. Bio Resources, 8(1): 427-446.

[16] Karim, A.K., Jalil, S., Triwahyono, N.H.N., Kamarudin, N.F.M., Salleh, (2012). Adsorption of Methylene Blue from Aqueous Solution by Mesostructured Silica nanoparticles," in Conference on Emerging Energy and Process Technology (CONCEPT).

[17] Ling, X., Li, J., Zhu, W., Zhu, Y., Sun, X., Shen, J., Han, W., Wang, L. (2012). Synthesis of Nano Scale Zero-Valent Iron/ordered Mesoporous Carbon For Adsorption and Synergistic Reduction of Nitrobenzene. Chemosphere, 87: 655-660.

[18] Hameed, A.K, Dewayanto, N., Dongyun, Du., Nordin, M.R. (2014). Synthesis and Characterization of Nano Scale Zero-ValentIron Supported on Mesoporous Silica. 9th Joint Conference on Chemistry, Indonesia. 
[19] Kirk, C.T. (1988). Quantitative Analysis of The Effect of Disorder-Induced Mode Coupling on Infrared Absorption in Silica. Physical Review B, 38 (2): 1255-1273.

[20] Kamitsos, E.I., Patsis, A.P., Kordas, G. (1993). Infrared-Reflectance Spectra of HeatTreated Sol-gel-Derived Silica. Physical Review B, 48(17): 12499-12505.

[21] Dimos, K., Antoniou, M.K., Meichanetzoglou, A., Lymperopoulou, S., Ouzouni, M.D., Koutselas, I.B., Fokas, D., Karakassides, M.A., Agostino, R.G., Gournis, D. (2012). Naphthalene-Based Periodic Nanoporous Organo Silicas: I. Synthesis and Structural Characterization. Microporous and Mesoporous Materials, 158: 324-331.

[22] Wang, L. and Li, J. (2013). Removal of Methylene Blue from Aqueous Solution by Adsorption onto Crofton Weed Stalk. Bio Recourse, 8(2): 2521-2536.

[23] Park, J., Han, Y., Kim, H. (2012). Formation of Mesoporous Materials from Silica dissolved in various $\mathrm{NaOH}$ concentrations: Effect of $\mathrm{pH}$ and ionic strength. Journal of Nanomaterials. 2012: 1-10.

[24] Noubactep, C., Care, S., Caren, R. (2012). Nano Scale Metallic Iron for Environmental Remediation: Prospects and limitations. Water Air Soil Pollutes. 223: 1363-1382.
[25] Peruchi, L.M., Fostier, A.H., Rath, S., (2014). Sorption of norfloxacin in soils: Analytical, kinetics and Freundlich isotherms. Chemosphere, 119C: 310-317.

[26] Gouamid, M., Ouahrani, M.R. Bensaci, M.B. (2013). Adsorption Equilibrium, Kinetics and Thermodynamics of Methylene Blue from Aqueous Solutions Using Date palm Leaves. Energy Procedia, 36: 898-907.

[27] Derakhshan, Z., Baghapour, M. (2013). Adsorption of Methylene Blue Dye from Aqueous Solutions by Modified Pumice Stone: Kinetics and Equilibrium Studies. Health Scope, 2(3): 136-44.

[28] ALzaydien, A.S. (2009). Adsorption of Methylene Blue from Aqueous Solution onto a LowCost Natural Jordanian Tripoli. American Journal of Applied Sciences, 6(6): 1047-1058.

[29] Abdel Ghafar, H.H., Ali, G.A.M., Fouad, O.A., Makhlouf, S.A. (2013). Enhancement of Adsorption Efficiency of Methylene Blue on $\mathrm{Co}_{3} \mathrm{O}_{4} / \mathrm{SiO}_{2}$ Nanocomposite. Desalination and Water Treatment, 53(11): 2980-2989.

[30] Wang, P., Cao, M., Wang, Ch., Ao, Y., Hou, J., Qian, J. (2014). Kinetics and Thermodynamics of Adsorption of Methylene Blue by a Magnetic Graphene-Carbon Nanotube Composite. Applied Surface Science, 290: 116-124.

Selected and Revised Papers from The International Conference on Fluids and Chemical Engineering (FluidsChE 2015) (http://fluidsche.ump.edu.my/index.php/en/) (Malaysia, 25-27 November 2015) after Peer-reviewed by Scientific Committee of FluidsChE 2015 and Reviewers of BCREC 